\title{
PEMANFAATAN TEKNOLOGI VIRTUAL REALITY (VR) PADA APLIKASI 3D BANGUNAN PERUSAHAAN
}

\author{
Andi Nur Rachman ${ }^{1}$, M. Adi Khairul Anshary², Ichsan Nurul Hakim ${ }^{3}$
}

${ }^{123}$ Universitas Siliwangi

Jl. Siliwangi No. 24, Tasikmalaya-Jawa Barat

1andy.rachman@unsil.ac.id, ${ }^{2}$ adikhairul@unsil.ac.id, ${ }^{3} 1570060022 @$ student.unsil.ac.id

\begin{abstract}
Abstrak- Aplikasi 3D objek dan teknologi virtual reality merupakan salah satu pemanfaatan teknologi multimedia interaktif. Dalam pembuatan aplikasi yang menggunakan objek 3D dan teknologi virtual reality, banyak fitur-fitur yang bisa dimanfaatkan salah satunya dengan memanfaatkan fitur gyroscope yang terdapat pada smartphone sebagai kegunaan sistem kendali dan interaksi pada aplikasi. Penelitian ini bertujuan memanfaatkan visualisasi objek 3D pada teknologi virtual reality menggunakan pemanfaatan fitur gyroscope sebagai alat untuk berinteraksi pada aplikasi, 3D objek yang digunakan yaitu bangunan dari perusahaan PT. ADD.Co untuk membantu mengenalkan suatu lingkungan bangunan perusahaan kepada calon investor atau pada calon pegawai baru secara visual. Metode yang digunakan pada penelitian ini adalah metode pengembangan multimedia versi Luther-Sutopo yang melalui beberapa tahap, seperti concept, design, material collecting, assembly, dan distribution. Berdasarkan hasil pengujian aplikasi, dalam tahapan pengujian alpha sudah baik sesuai fungsionalitas, dan pada tahap pengujian beta didapat nilai $81,4 \%$ dalam interval "sangat baik" sebagai aplikasi yang layak untuk digunakan pengguna dalam mengenalkan suatu lingkungan bangunan perusahaan secara visual.
\end{abstract}

Kata Kunci- 3D, Gyroscope, Virtual Reality.

Abstract- Application of 3D objects and virtual reality technology is one of the utilization of interactive multimedia technology. In making applications that use $3 D$ objects and virtual reality technology, many features can be utilized, one of which is by utilizing the gyroscope feature found on smartphones as a control system and application interaction. This study aims to utilize 3D object visualization on virtual reality technology using the gyroscope feature as a tool to interact with the application, 3D objects used are buildings of the company PT. ADD.Co to help visually introduce a company building environment to prospective investors or prospective new employees. The method used in this research is the Luther-Sutopo version of multimedia development methods that go through several stages, such as concept, design, material collecting, assembly, and distribution. Based on the results of application testing, the alpha testing stage is good according to functionality, and in the beta testing phase, it is found that the value of $\mathbf{8 1 . 4 \%}$ in the "very good" interval is a feasible application for users to introduce in a company building environment visually.

Keywords-3D, Gyroscope, Virtual Reality.

\section{PENDAHULUAN}

Gambar 3-dimensi atau biasa disebut dengan 3D, dalam perkembangannya saat ini sudah sangat pesat. Grafik 3D merupakan perkembangan dari grafik 2D yaitu grafik yang berpatokan pada dua titik yang menentukan panjang dan lebar dari suatu objek berkembang menjadi bentuk 3D, yaitu memiliki patokan pada tiga titik yang menentukan panjang, lebar dan tinggi dari suatu objek [1].

Virtual reality merupakan salah satu teknologi yang dimanfaatkan dalam ilmu teknologi informasi menggunakan gambar 3D dalam memvisualisasikan hasil dari gambar 3D. Virtual reality (VR) adalah teknologi yang memungkinkan seseorang melakukan simulasi terhadap suatu objek nyata dengan menggunakan komputer yang mampu membangkitkan suasana 3D sehingga membuat pengguna seolah terlibat secara fisik [2]

Penelitian yang dilakukan oleh [3], telah mengimplementasikan objek 3D katalog perumahan dengan teknologi virtual reality (VR). Pada penelitian tersebut, virtual reality dimanfaatkan dengan menggunakan fitur point tracking yang digunakan untuk mengobservasi setiap sudut ruangan pada objek 3D serta pada hasil aplikasi yang dibuat hanya dapat dijalankan pada perangkat smartphone android Samsung tipe $S$ serta menggunakan alat tambahan Samsung Gear VR sebagai kontrol interaksi dalam aplikasi virtual reality.

Point tracking merupakan salah satu fungsi yang digunakan pada aplikasi aplikasi virtual reality, fungsi ini digunakan salah satunya untuk mengobservasi lingkungan aplikasi virtual reality dengan cara 
pengguna mengarahkan pandangan atau sensor pada alat VRgear pada suatu titik atau tombol yang telah dibuat pada aplikasi virtual reality sehingga pengguna bisa berpindah dari satu titik koordinat ke koordinat yang lain pada satu lingkungan virtual reality.

Gyroscope adalah sensor yang digunakan untuk mendeteksi rotasi dari suatu perangkat berdasarkan gerakan fisik yang terjadi pada perangkat tersebut. Alat ini bekerja sama dengan accelerometer (sensor pengukur pergerakan perangkat sesuai dengan tiga sumbu XYZ atau atas-bawah, kanan-kiri, depanbelakang) untuk fitur seperti memiringkan atau memutar ponsel (Larashati, Ester, 2017)[4].

Berdasarkan hasil penelitian [3], maka dapat dikembangkan pada penelitian yang akan dilakukan dengan memanfaatkan fitur lain pada aplikasi virtual reality seperti fitur point tracking yang bisa diganti dengan fitur gyroscope pada smartphone sebagai kontrol interaksi dalam aplikasi 3D dan hasil aplikasi yang dibuat bisa dijalankan di banyak smartphone android dengan menggunakan alat VRbox. Pada penelitian ini menggunakan objek 3D dari bangunan perusahaan PT. ADD.Co yang juga diharapkan dapat membantu perusahaan dalam memperkenalkan lingkungan gedung perusahaan kepada para calon investor atau kepada calon pegawai perusahaan.

Rumusan masalah yang menjadi pokok dalam penelitian ini yaitu :

1. Bagaimana cara memvisualisasikan gambar 3D bangunan PT. ADD.Co pada aplikasi virtual reality?

2. Bagaimana cara memanfaatkan fitur gyroscope pada smartphone android dengan aplikasi virtual reality?

3. Bagaimana cara mengimplementasikan hasil aplikasi virtual reality menggunakan VRbox?

Tujuan yang ingin dicapai dalam penelitian dikemukakan, sebagai berikut :

1. Memvisualisasikan gambar 3D bangunan PT. ADD.Co pada aplikasi virtual reality.

2. Dapat memanfaatkan fitur gyroscope pada smartphone dengan aplikasi virtual reality.

3. Mengimplementasikan hasil aplikasi virtual reality menggunakan VRbox.

\section{METODOLOGI}

Alur metode penelitian yang digunakan dalam penelitian ini menggunakan kerangka penelitian sebagai berikut:

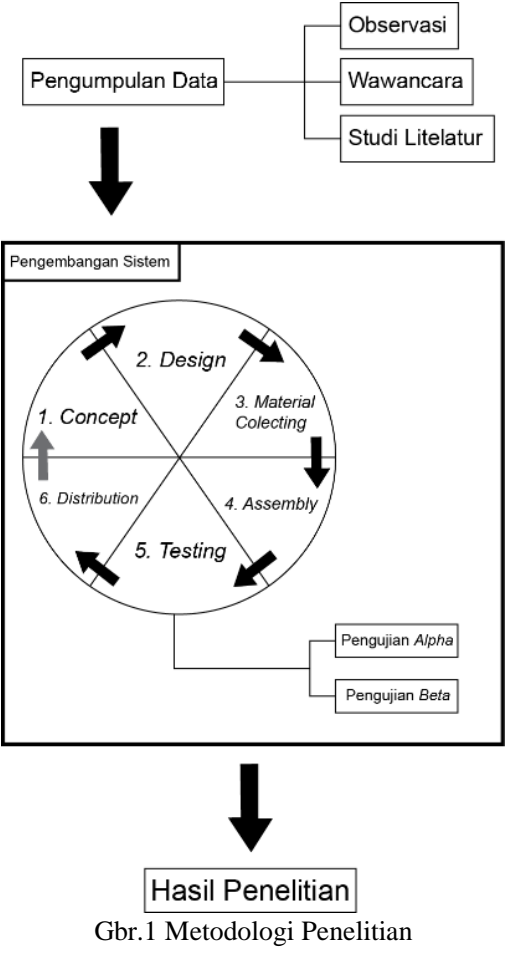

\section{A. Pengumpulan Data}

Pengumpulan data ini ditujukan untuk mengumpulkan data dan bahan apa saja yang akan mendukung dalam pembuatan aplikasi ini. Teknik yang digunakan dalam melakukan pengumpulan data diantaranya, yang pertama adalah pengumpulan data dengan observasi, Dari hasil observasi ini didapat informasi yang mendukung berjalan nya penelitian yaitu desain bangunan perusahaan $2 \mathrm{D}$ dan $3 \mathrm{D}$, serta file 3D bangunan perusahaan. Yang kedua wawancara, untuk menanyakan kondisi atau permasalahan yang dialami pada perusahaan, dan yang ketiga adalah studi literature yaitu uraian penelitian tentang mengimplementasikan teknologi virtual reality dari sudut pandang teoritis atau keilmuan nya dengan melakukan pencarian berbagai referensi pendukung pelaksana teknis dengan mempelajari artikel-artikel dan jurnal ilmiah nasional maupun internasional tentang virtual reality, kemudian dilakukan pengkajian terhadap penelitian-penelitian sebelumnya dengan menyesuaikan referensi yang diperoleh untuk sebuah solusi pembuatan sistem.

\section{B. Pengembangan system}

Dalam pengembangan sistem, metode penelitian yang digunakan adalah metode Luther-Sutopo (2003), metode ini terdiri dari Concept, Design, Material Collecting, Assembly, Testing, Distribution. Metode ini dipilih karena dianggap sudah sesuai dengan penelitian yang digunakan dalam proses pembuatan aplikasi pemanfaatan teknologi virtual reality pada objek 3D bangunan perusahaan.

\section{Hasil Penelitian}

Hasil Penelitian dari beberapa proses mulai dari pengumpulan data sampai pengembangan sistem yang 
telah dilakukan, kemudian dikelompokkan hingga menghasilkan aplikasi yang sesuai dengan keseluruhan rangkaian metode penelitian.

\section{HASIL DAN PEMBAHASAN}

\section{A. Concept}

Konsep utama dari aplikasi ini yaitu memvisualisasikan objek 3D bangunan perusahaan menggunakan teknologi virtual reality dengan memanfaatkan fitur gyroscope pada smartphone. Berikut penjelasan spesifikasi konsep pemuatan aplikasi yang akan dijelaskan pada tabel I.

TABEL I

DESKRIPSI KONSEP

\begin{tabular}{|l|l|}
\hline \multicolumn{1}{|c|}{ Item } & \multicolumn{1}{|c|}{ Spesifikasi } \\
\hline Judul & ADD.Co Virtual Reality \\
\hline Audiens & Umum \\
\hline Durasi & \pm 15 menit \\
\hline Teks & Informasi Objek Bangunan \\
\hline Objek & 3-Dimensi \\
\hline Interaktifitas & Tombol \\
\hline Deskripsi & $\begin{array}{l}\text { Aplikasi untuk pengenalan lingkungan } \\
\text { objek 3D bangunan perusahan PT. } \\
\text { ADD.Co dalam visualisasi digital } \\
\text { menggunakan teknologi virtual reality. }\end{array}$ \\
\hline
\end{tabular}

B. Design

Tahapan perancangan ini menjelaskan alur proses pada pembuatan aplikasi virtual reality objek 3D bangunan perusahaan, pemodelan ini menggunakan UML Diagram, dan struktur navigasi. UML diagram yang digunakan pada penelitian ini adalah Use Case Diagram, dan Sequence Diagram.

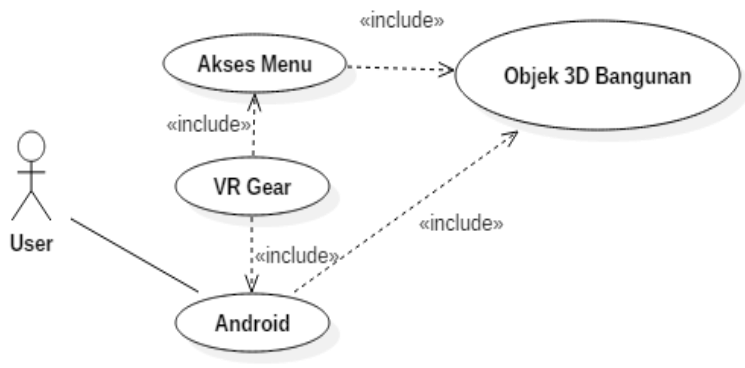

Gbr.2 Use Case Diagram

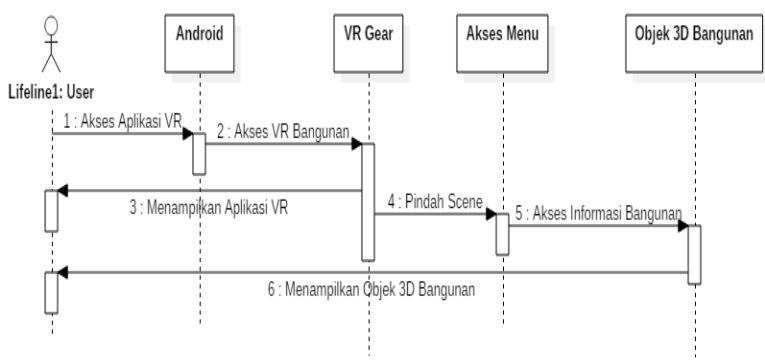

Gbr.3 Sequence Diagram

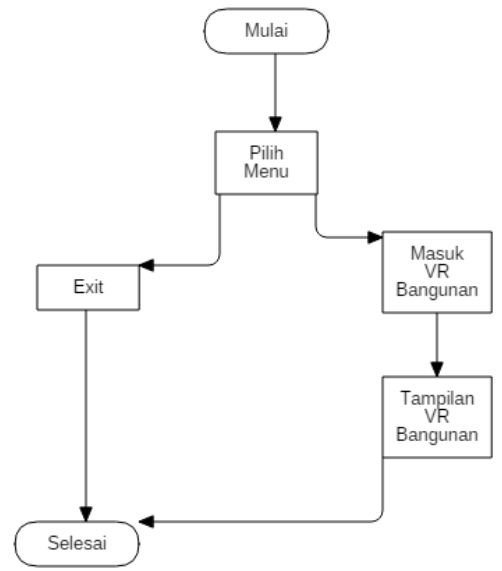

Gbr.4 Flow Chart Diagram

\section{Material Collecting}

Pada tahapan ini menguraikan apa saja bahanbahan yang harus tersedia dalam pembuatan aplikasi virtual reality, yaitu sebagai berikut:

\section{Objek 3D Bangunan}

Tahapan material collecting pada pengembangan aplikasi VR yaitu objek rumah 3D yang didapat dari PT. ADD.Co dijadikan sebagai lingkungan virtual pada aplikasi. Objek rumah 3D yang sudah dilengkapi dengan tekstur yang membuat tampilannya terlihat lebih nyata, dilanjutkan pada proses pembuatan aplikasi.

\section{Data Informasi}

Pada aplikasi ini terdapat fitur informasi bangunan seperti informasi apa itu ADD.Co, dan informasi tentang tempat-tempat yang dijadikan objek informasi pada aplikasi.

3. Data Suara

Dalam aplikasi ini terdapat data suara agar dapat menimbulkan interaktifitas yang lebih baik, serta dapat mendukung suasana dalam suatu lingkungan seperti aslinya.

\section{Data Gambar}

Pada aplikasi ini terdapat penggunaan gambar sebagai pendukung dalam membangun konten yang terdapat aplikasi. Data gambar untuk keperluan aplikasi ini diambil sebagian dari perusahaan dan sedikit modifikasi untuk mendukung pembuatan tampilan aplikasi, format ekstensi yang digunakan *.jpg dan *.png. Berikut tabel daftar data gambar yang digunakan pada pembuatan aplikasi. 
TABEL II

DATA GAMBAR

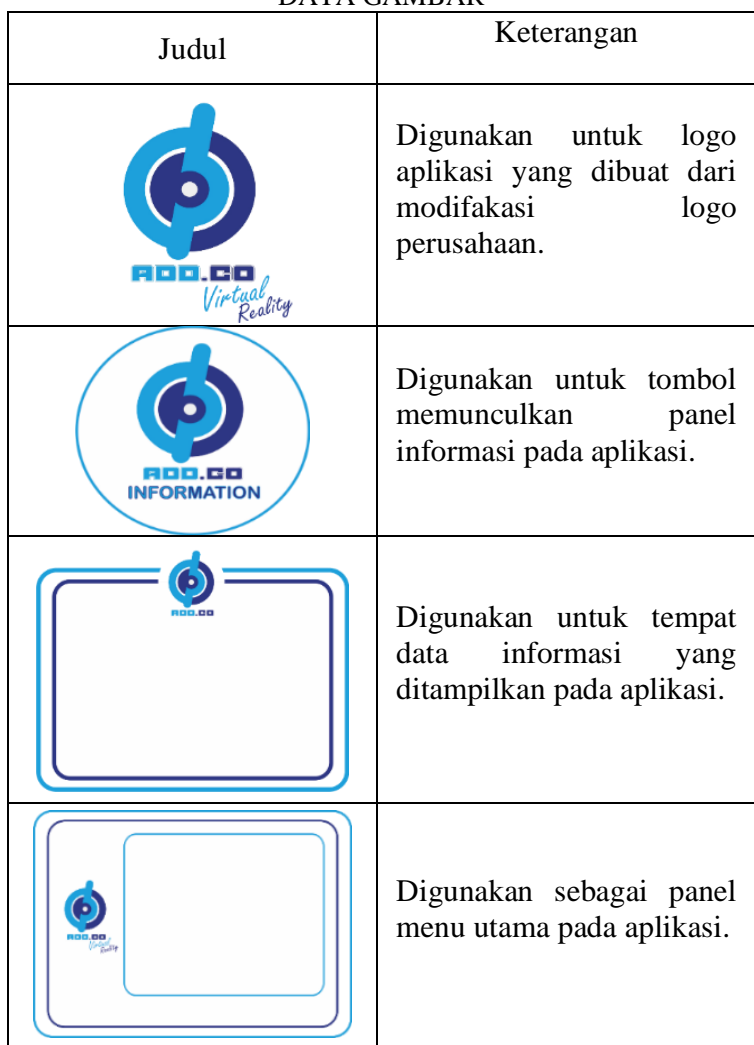

\section{Assembly}

Tahap assembly menggabungkan material yang sudah dikumpulkan menjadi sebuah aplikasi berdasarkan rancangan konsep dan desain pada tahap sebelumnya. Berikut hasil dari tahapan assembly :

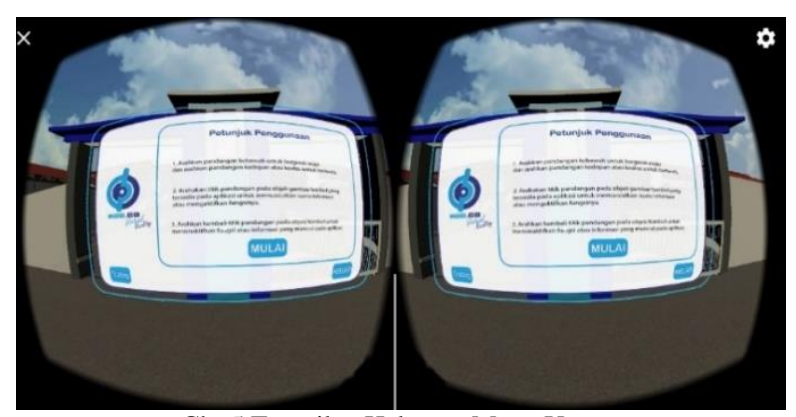

Gbr.5 Tampilan Halaman Menu Utama

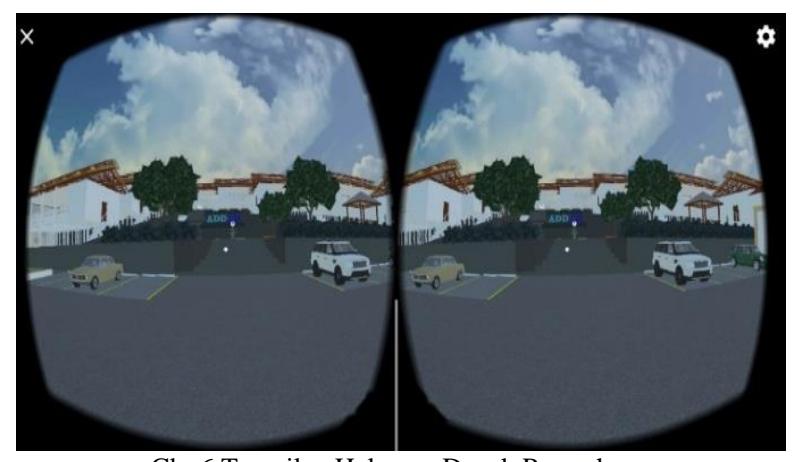

Gbr.6 Tampilan Halaman Denah Perusahaan

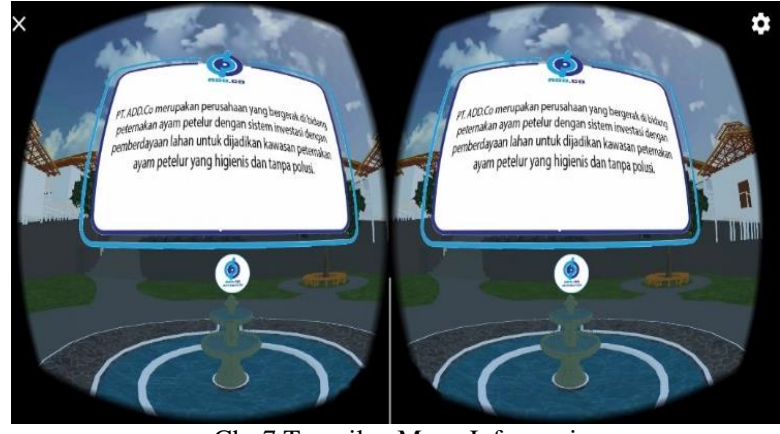

Gbr.7 Tampilan Menu Informasi

E. Testing

Tahapan testing ialah Tahap dimana aplikasi memasuki pengujian. Pengujian yang dilakukan meliputi pengujian alpa dan pengujian beta.

\section{Alpha Test}

Pengujian Alpha dilakukan oleh pengembang dengan metode Black-Box Testing. Kesimpulan dari Alpha test bahwa semua fungsi pada aplikasi berjalan dengan baik.

\section{Beta Test}

Pengujian Beta pada tahap ini yaitu, pengambilan data survei dengan cara mengisi kuesioner. Pengujian Beta dilakukan untuk mendapatkan fungsi dengan mempertimbangkan aspek pembelajaran informasi, yaitu VISUALS yaitu visible, interesting, simple, useful, accurate, legitimate, dan structure.

Pengambilan sampel dalam penelitian ini menggunakan teknik insidental (Kebetulan) dimana populasi direncanakan dan samplenya yaitu mahasiswa Informatika Angkatan 2015 Universitas Siliwangi menggunakan rumus slovin. Hasil pengambilan data didapat sebanyak 100 populasi dari Mahasiswa Informatika Universitas Siliwangi dengan margin error $15 \%$ menghasilkan 30 sample. Perhitungan untuk kuesioner menggunakan skala likert, dimana setiap pernyataan mempunyai bobot nilai berikut adalah bobot nilai skala likert.

\begin{tabular}{c|l|}
\multicolumn{2}{c}{ TABEL III } \\
\multicolumn{1}{c|}{ SKALA LIKERT } \\
\hline Skor & \multicolumn{1}{c|}{ Keterangan } \\
\hline 5 & Sangat Baik \\
\hline 4 & Baik \\
\hline 3 & Cukup \\
\hline 2 & Kurang \\
\hline 1 & Sangat Kurang \\
\hline
\end{tabular}

Untuk mencari persentase dari masing-masing jawaban kuesioner digunakan rumus skala likert sebagai berikut:

$$
P=\frac{S}{\text { Skor Ideal }} \times 100 \%
$$

Dimana $\mathrm{P}$ adalah Nilai Persentase yang dicari, $\mathrm{S}$ adalah Jumlah Frekuensi dikalikan dengan skor total jawaban, Skor Ideal adalah Nilai tertinggi dikali jumlah sample. Sedangkan hasil persentase 
perhitungan kuesioner yang sudah diberikan kepada responden adalah sebagai berikut:

TABEL IV

HASIL PENGUMPULAN DATA DAN PERHITUNGAN VISIBLE

\begin{tabular}{|c|c|c|c|c|c|c|c|c|}
\hline \multirow{2}{*}{$\begin{array}{c}\text { Aspek } \\
\text { Pengujian }\end{array}$} & \multirow{2}{*}{ Pernyataan } & \multicolumn{5}{|c|}{ Penilain } & \multirow{2}{*}{$\begin{array}{l}\text { Total } \\
\text { Skor }\end{array}$} & \multirow{2}{*}{$\begin{array}{c}\text { Hasil } \\
\text { Presentase }\end{array}$} \\
\hline & & SB & B & \begin{tabular}{c|c} 
C \\
\end{tabular} & $\mathrm{K}$ & SK & & \\
\hline \multirow{3}{*}{ Visible } & $\begin{array}{l}\text { Visualisasi objek 3D dalam } \\
\text { aplikasi terlihat jelas }\end{array}$ & 9 & 19 & 2 & - & - & 127 & $84,6 \%$ \\
\hline & $\begin{array}{l}\text { Gambar atau grafis dalam aplikasi } \\
\text { terlihat jelas }\end{array}$ & 6 & 22 & 2 & - & - & 124 & $82,6 \%$ \\
\hline & $\begin{array}{l}\text { Visualisasi seluruh tampilan pada } \\
\text { aplikasi dapat dimengerti dengan } \\
\text { baik }\end{array}$ & 13 & 13 & 4 & - & - & 129 & $86 \%$ \\
\hline \multicolumn{8}{|c|}{ Rata-rata Hasil Presentase } & $84,4 \%$ \\
\hline
\end{tabular}

TABEL $V$

HASIL PENGUMPULAN DATA DAN PERHITUNGAN INTERISTING

\begin{tabular}{|c|c|c|c|c|c|c|c|c|}
\hline \multirow{2}{*}{$\begin{array}{l}\text { Aspek } \\
\text { Pengujian }\end{array}$} & \multirow{2}{*}{ Pernyataan } & \multicolumn{5}{|c|}{ Penilaian } & \multirow{2}{*}{$\begin{array}{l}\text { Total } \\
\text { Skor }\end{array}$} & \multirow{2}{*}{$\begin{array}{c}\text { Hasil } \\
\text { Presentase }\end{array}$} \\
\hline & & SB & B & C & $\mathrm{K}$ & SK & & \\
\hline \multirow{3}{*}{ Interisting } & $\begin{array}{l}\text { Visualisasi objek 3D pada aplikasi } \\
\text { sesuai kebutuhan pengguna }\end{array}$ & 6 & 14 & 10 & - & - & 116 & $77,3 \%$ \\
\hline & $\begin{array}{l}\text { Tampilan aplikasi bisa } \\
\text { menimbulkan rasa ingin tahu }\end{array}$ & 7 & 18 & 4 & 1 & - & 121 & $80,6 \%$ \\
\hline & $\begin{array}{l}\text { Interakttifitas visualisasi pada } \\
\text { aplikasi dapat dipahami pengguna }\end{array}$ & 8 & 15 & 7 & - & - & 121 & $80,6 \%$ \\
\hline \multicolumn{8}{|c|}{ Rata-rata Hasil Presentase } & $79,5 \%$ \\
\hline
\end{tabular}

TABEL VI

HASIL PENGUMPULAN DATA DAN PERHITUNGAN SIMPLE

\begin{tabular}{|c|c|c|c|c|c|c|c|c|}
\hline \multirow{2}{*}{$\begin{array}{l}\text { Aspek } \\
\text { Pengujian }\end{array}$} & \multirow{2}{*}{ Pernyataan } & \multicolumn{5}{|c|}{$\begin{array}{l}\text { Penilaian } \\
\end{array}$} & \multirow{2}{*}{$\begin{array}{l}\text { Total } \\
\text { Skor }\end{array}$} & \multirow{2}{*}{$\begin{array}{c}\text { Hasil } \\
\text { Presentase }\end{array}$} \\
\hline & & SB & B & & $\mathrm{K}$ & SK & & \\
\hline \multirow{3}{*}{ Simple } & $\begin{array}{l}\text { Visualisasi yang disampaikan } \\
\text { fokus pada inti dari aplikasi }\end{array}$ & 8 & 13 & 9 & & & 119 & $79,3 \%$ \\
\hline & $\begin{array}{l}\text { Bahasa yang digunakan didalam } \\
\text { aplikasi sederhana dan mudah } \\
\text { dimengerti }\end{array}$ & 10 & 16 & 4 & - & - & 126 & $84 \%$ \\
\hline & $\begin{array}{l}\text { Pengguna dapat menjalankan } \\
\text { aplikasi tanpa kesulitan }\end{array}$ & 5 & 20 & 4 & 1 & - & 119 & $79,3 \%$ \\
\hline & $80,8 \%$ \\
\hline
\end{tabular}

TABEL VII

HASIL PENGUMPULAN DATA DAN PERHITUNGAN USEFUL

\begin{tabular}{|c|c|c|c|c|c|c|c|c|}
\hline \multirow{2}{*}{$\begin{array}{l}\text { Aspek } \\
\text { Pengujian }\end{array}$} & \multirow{2}{*}{ Pernyataan } & \multicolumn{5}{|c|}{ Penilaian } & \multirow{2}{*}{$\begin{array}{l}\text { Total } \\
\text { Skor }\end{array}$} & \multirow{2}{*}{$\begin{array}{c}\text { Hasil } \\
\text { Presentase }\end{array}$} \\
\hline & & SB & B & $\mathrm{C}$ & $\mathrm{K}$ & SK & & \\
\hline \multirow{5}{*}{ Useful } & $\begin{array}{l}\begin{array}{l}\text { Visualisasi } \\
\text { dioperasikan }\end{array} \\
\text { aplikasi } \\
\text { mudah }\end{array}$ & 6 & 21 & 2 & 1 & - & 122 & $81,3 \%$ \\
\hline & $\begin{array}{l}\text { Pemanfaatam fitur gyroscope pada } \\
\text { aplikasi mempermudah dalam } \\
\text { mengontrol aplikasi saat melakukan } \\
\text { observasi dalam aplikasi. }\end{array}$ & 10 & 15 & 5 & - & - & 125 & $83,3 \%$ \\
\hline & $\begin{array}{l}\text { Penggunaan aplikasi sudah sesuai } \\
\text { dengan konsep aplikasi }\end{array}$ & 8 & 17 & 5 & - & - & 123 & $82 \%$ \\
\hline & $\begin{array}{l}\text { Tombol pada aplikasi berjalan } \\
\text { sesuai fungsinya }\end{array}$ & 10 & 16 & 4 & - & - & 126 & $84 \%$ \\
\hline & $\begin{array}{l}\text { Fitur didalam aplikasi membantu } \\
\text { pengguna dalam menemukan } \\
\text { informasi yang terdapat pada } \\
\text { aplikasi }\end{array}$ & 8 & 16 & 6 & - & - & 122 & $81,3 \%$ \\
\hline \multicolumn{8}{|c|}{ Rata-rata Hasil Presentase } & $82,3 \%$ \\
\hline
\end{tabular}

TABEL VIII

HASIL PENGUMPULAN DATA DAN PERHITUNGAN ACCURATE

\begin{tabular}{|c|c|c|c|c|c|c|c|c|}
\hline \multirow{2}{*}{$\begin{array}{l}\text { Aspek } \\
\text { Pengujian }\end{array}$} & \multirow[b]{2}{*}{ Pernyataan } & \multirow{2}{*}{\multicolumn{5}{|c|}{$\begin{array}{l}\text { Penilaian } \\
\end{array}$}} & \multirow{2}{*}{$\begin{array}{l}\text { Total } \\
\text { Skor } \\
\end{array}$} & \multirow{2}{*}{$\begin{array}{c}\text { Hasil } \\
\text { Presentase } \\
\end{array}$} \\
\hline & & SB & & & & SK & & \\
\hline \multirow{3}{*}{ Accurate } & $\begin{array}{l}\text { Penempatan tampilan visualisasi } \\
\text { objek } 3 \mathrm{D} \text { didalam aplikasi sudah } \\
\text { sesuai dan benar }\end{array}$ & 8 & 17 & 5 & - & & 123 & $82 \%$ \\
\hline & 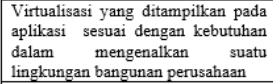 & 6 & 21 & 3 & - & - & 123 & $82 \%$ \\
\hline & 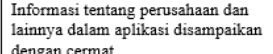 & 5 & 19 & 6 & - & - & 119 & $79,3 \%$ \\
\hline \multicolumn{8}{|c|}{ Rata-rata Hasil $\mathrm{I}$} & $81,1 \%$ \\
\hline
\end{tabular}

TABEL IX

HASIL PENGUMPULAN DATA DAN PERHITUNGAN LEGITIMATE

\begin{tabular}{|c|c|c|c|c|c|c|c|c|}
\hline \multirow{2}{*}{$\begin{array}{c}\text { Aspek } \\
\text { Pengujian }\end{array}$} & \multirow{2}{*}{ Pernyataan } & \multicolumn{5}{|c|}{ Penilaian } & \multirow{2}{*}{$\begin{array}{l}\text { Total } \\
\text { Skor }\end{array}$} & \multirow{2}{*}{$\begin{array}{c}\text { Hasil } \\
\text { Presentas }\end{array}$} \\
\hline & & SB & B & $\mathrm{C}$ & $\mathrm{K}$ & SK & & \\
\hline \multirow{4}{*}{ Legitimate } & $\begin{array}{l}\text { Aplikasi memberikan pesan atau } \\
\text { visualisasi yang benar seputar } \\
\text { pengenalan lingkungan bangunan } \\
\text { perusahaan }\end{array}$ & 6 & 21 & 2 & 1 & - & 122 & $81,3 \%$ \\
\hline & $\begin{array}{l}\text { Objek 3D dan gambar yang } \\
\text { ditampilkan disusun secara logis }\end{array}$ & 10 & 17 & 3 & - & - & 127 & $84,6 \%$ \\
\hline & $\begin{array}{l}\text { Konsep aplikasi virtualisasi objek } \\
\text { 3D bangungan perusahaan } \\
\text { mengikuti kaidah keilmuan }\end{array}$ & 6 & 18 & 6 & - & - & 120 & $80 \%$ \\
\hline & $\begin{array}{l}\text { Konsep virtualisasi objek 3D } \\
\text { bangunan perusahaan pada aplikasi } \\
\text { masuk akal }\end{array}$ & 8 & 20 & 2 & - & - & 126 & $84 \%$ \\
\hline \multicolumn{8}{|c|}{ Rata-rata Hasil Presentase } & $82,4 \%$ \\
\hline
\end{tabular}

TABEL $X$

HASIL PENGUMPULAN DATA DAN PERHITUNGAN STRUCTURE

\begin{tabular}{|c|c|c|c|c|c|c|c|c|}
\hline \multirow{2}{*}{$\begin{array}{c}\text { Aspek } \\
\text { Pengujian }\end{array}$} & \multirow{2}{*}{ Pernyataan } & \multicolumn{5}{|c|}{ Penilaian } & \multirow{2}{*}{$\begin{array}{l}\text { Total } \\
\text { Skor }\end{array}$} & \multirow{2}{*}{$\begin{array}{c}\text { Hasil } \\
\text { Presentase }\end{array}$} \\
\hline & & SB & B & $\mathrm{C}$ & $\mathrm{K}$ & SK & & \\
\hline \multirow{2}{*}{ Structure } & $\begin{array}{l}\text { Rangkaian pesan informasi pada } \\
\text { aplikasi disampaiakan secara } \\
\text { sistematis }\end{array}$ & 5 & 17 & 7 & 1 & - & 116 & $77,3 \%$ \\
\hline & $\begin{array}{l}\text { Urutan konsep aplikasi logis dan } \\
\text { mudah dipahami }\end{array}$ & 6 & 21 & 3 & - & - & 123 & $82 \%$ \\
\hline \multicolumn{8}{|c|}{ Rata-rata Hasil Presentase } & $79,6 \%$ \\
\hline
\end{tabular}

Untuk melakukan perhitungan persentase keseluruhan digunakan rumus sebagai berikut:

$P K=\Sigma$ persentase pernyataan sample / $\Sigma$ persentase keseluruhan

Dimana PK adalah Nilai Persentase Keseluruhan yang dicari, $\Sigma$ persentase pernyataan sample dibagi $\Sigma$ persentase keseluruhan S. Sedangkan hasil persentase perhitungan persentase keseluruhan kuesioner yang sudah diberikan kepada responden adalah sebagai berikut:

TABEL XI

HASIL PERHITUNGAN VISUALS

\begin{tabular}{|c|c|}
\hline Aspek Pernyataan & Persentase \\
\hline Visible & $84,4 \%$ \\
\hline Interesting & $79,5 \%$ \\
\hline Simple & $80,8 \%$ \\
\hline Useful & $82,3 \%$ \\
\hline Accurate & $81,1 \%$ \\
\hline Legitimate & $82,4 \%$ \\
\hline Structure & $79,6 \%$ \\
\hline Rata-rata Persentase Keseluruhan & $\mathbf{8 1 , 4 \%}$ \\
\hline
\end{tabular}

Hasil perhitungan persentase keseluruhan aplikasi virtual tour mendapatkan persentase sebesar $81,4 \%$ dan masuk dalam kategori sangat baik. Skala kategori dapat dilihat pada tabel XII.

TABEL XII

INTERPRETASI SKOR BERDASARKAN INTERVAL

\begin{tabular}{|c|l|}
\hline Persentase & \multicolumn{1}{|c|}{ Keterangan } \\
\hline $80 \%-100 \%$ & Sangat Baik \\
\hline $60 \%-79.9 \%$ & Baik \\
\hline $40 \%-59,9 \%$ & Cukup \\
\hline $20 \%-39,9 \%$ & Kurang \\
\hline $0 \%-19,9 \%$ & Sangat Kurang \\
\hline
\end{tabular}

\section{F. Distribution}

Aplikasi yang sudah selesai dibuat kemudian di build berupa file apk dengan ukuran 96 MB yang nantinya aplikasi dapat dijalankan di smartphone dengan operating system Android. Penyaluran aplikasi 
ini tidak disebar secara umum, aplikasi ini diperuntukkan hanya untuk kebutuhan perusahaan untuk membantu dalam mengenalkan lingkungan bangunan kepada calon investor atau kepada calon pegawai baru perusahaan. Dalam pendistribusian aplikasi selain dari bentuk file .apk, perusahaan diberi E-Manual Book untuk membantu dalam penggunaan aplikasi yang bisa dilihat pada link bit.ly/3aKLLHQ.

\section{G. Kelebihan dan Kekurangan}

Kelebihan dari aplikasi virtual reality objek 3D bangunan perusahaan yang telah dibangun adalah sebagai berikut:

1. Navigasi pada aplikasi sangat mudah digunakan karena memanfaatkan fitur gyroscope pada smartphone, sehingga tidak perlu memerlukan controller tambahan.

2. Interface yang disajikan secara userfriendly agar dapat digunakan dengan mudah oleh pengguna.

3. Informasi yang awalnya berbentuk deskripsi dan disajikan dalam bentuk teks, pada aplikasi ini disajikan dengan menggunakan elemen multimedia gambar dan suara.

Sedangkan kekurangan dari aplikasi virtual reality objek 3D bangunan perusahaan yang telah dibangun adalah sebagai berikut:

1. Untuk sebagian pengguna yang menderita mabuk kendaraan, saat penggunaan aplikasi ini menimbulkan efek mual dan pusing. Namun sudah menjadi risiko yang akan dihadapi apabila interaksi dengan dunia tiga dimensi memang akan menimbulkan efek pusing.

2. Aplikasi akan terasa berat ketika dijalankan pada smartphone yang memiliki kapasatias memori yang kecil.

3. Interaksi aplikasi dengan pengguna masih hanya sebatas melakukan observasi lingkungan virtual dan melihat informasi yang tertera.

\section{KESIMPULAN DAN SARAN}

Berdasarkan hasil penelitian yang telah dilakukan dapat diambil kesimpulan sebagai berikut:

1. Membantu dalam memperkenalkan lingkungan bangunan perusahaan kepada calon investor atau kepada calon pegawai perusahaan secara memvisualisasikan bangunan perusahaan dengan teknologi virtual reality.

2. Telah berhasil merancang dan membangun aplikasi virtual reality objek 3D bangunan perusahaan dengan menggunakan metode pengembangan Luther-Sutopo, serta berhasil memanfaatkan fitur gyroscope pada smartphone sebagai navigasi pada aplikasi sehingga tidak memerlukan controller tambahan untuk menggunakan aplikasi.

3. Pengukuran tingkat keberhasilan aplikasi yang layak digunakan pengguna, dilakukan dengan pengujian Beta yang hasilnya menunjukan presentase $81,4 \%$ dalam kriteria "sangat baik" sebagai indikator keberhasilan dibangunnya aplikasi ini.

Adapun saran yang dapat dikemukakan agar untuk kedepannya menjadi perbaikan dan pertimbangan adalah sebagai berikut:

1. Interkatifitas pada aplikasi lebih diperbanyak sehingga tidak terbatas hanya melakukan observasi saja dan melihat informasi yang tertera.

2. Menyajikan informasi aplikasi kedalam bentuk audio atau animasi bergerak agar lebih atraktif.

3. Produk aplikasi hanya bisa dijalankan pada perangkat android saja, akan menjadi lebih baik apabila dapat di implementasikan ke berbagai OS smartphone lainnya, seperti iOS, dan Windows.

\section{UCAPAN TERIMA KASIH}

Terimakasih saya ucapkan kepada orangtua, keluarga, dosen pembimbing serta semua pihak yang telah membantu serta mendoakan kelancaran penelitian.

\section{REFERENSI}

[1] Lengkong, O., Mema, H. P., and Tandayu, Y. E.," Aplikasi Denah 3D dan Navigasi Pada Gedung Manado Town Square Menggunakan Game Engine Berbasis Android. Minahasa", Cogito Smart Journal, Vol . 3, 2017

[2] Wardijono, B., Hendajani, F., S.A.Sudiro, and Ramadhani, A.,"Pengembangan Model Grafik 3 Dimensi Monumen Nasional Dan Lingkungan Sekitarnya. Jakarta", Seminar Nasional Sains dan Teknologi 2015 Fakultas Teknik Universitas Muhammadiyah Jakarta, 2015.

[3] Ramdani, C. M., Anshary, M. A., Rachman, A. N., and Munggary, L. N., "Implementation of Kampoeng Hijrah Residence Housing Catalog Based on Virtual Reality", 2nd International Conference of Computer and Informatics Engineering (IC2IE), 2019.

[4] Larashati, C. P., and Lumba, E., "Pengembangan Program Aplikasi Untuk Membantu Menghafal Perkalian Menggunakan Teknologi Virtual Reality Berbasis Android. Jakarta", Seminar Nasional Sains dan Teknologi Fakultas Teknik Universitas Muhammadiyah Jakarta, 2019.

[5] Bhaskara, S. G., Buana, P. W., and Purnawan, I. K., "Permainan Edukasi Labirin Virtual Reality Dengan Metode Collision Detection Dan Stereoscopic", LONTAR KOMPUTER, Vol 8, 2017.

[6] Binanto, I., Multimedia Digital - Dasar Teori dan Pengembangannya, Yogyakarta, 2010.

[7] Kusumaningsih, A., Angkoso, C. V., and Anggraeny, N., "Virtual Reality Museum Sunan Drajat Lamongan Berbasis Rule-Based System Untuk Pembelajaran Sejarah", Jurnal Teknologi Informasi dan Ilmu Komputer (JTIIK), Vol.5, 2018

[8] Purnomo, F. A., Pratisto, E. H., and Yasir, R. A., "Pembuatan Ruang Pamer 3 Museum Sangiran Menggunakan Teknologi Virtual Reality Berbasis Android", Simposium Nasional RAPI $X V, 2016$.

[9] Rambing, X., Tulenan, V., \& Najoan, X., "Virtual Reality Berbasis Video 360 Derajat pada Tari-Tarian Adat Suku Minahasa", E-Journal Teknik Informatika, Vol. 11, 2017.

[10] Sugiyono, Metode Penelitian Kuantitatif Kualitatif dan R\&D. Bandung, 2012 